\title{
CARMINA PARA HONORATO, OBISPO DE HISPALIS: LA POLÉMICA INSCRIPCIÓN DEL SUCESOR DE SAN ISIDORO
}

POR

\author{
HELENA GIMENO PASCUAL \\ Centro CIL II (Alcalá de Henares) \\ MÓNICA MIRÓ VINAIXA \\ Universidad de Barcelona
}

\section{RESUMEN}

En la catedral de Sevilla se conserva una inscripción atribuida al obispo Honorato, el sucesor de Isidoro en la silla episcopal hispalense. Mientras que, a partir de las fuentes literarias, es incuestionable que Honorato fue efectivamente el sucesor de Isidoro, las fuentes epigráficas de las que disponemos sobre el mismo personaje no permiten, por sus características, ser utilizadas documentalmente para la reconstrucción de su biografía, sobre todo una de ellas, que, como analizamos a continuación, no es una realización antigua.

\section{SUMMARY}

The Cathedral of Sevilla keeps an inscription which is attributed to Bishop Honoratus, the successor of Isidorus in the Hispalis episcopal siege. According to literary sources, it is unquestionable that Honoratus was effectively the successor of Isidorus, but the epigraphic evidence does not allow the biographical reconstruction, and in particular one of these inscriptions, as the following analysis shows, is not an ancient work.

\section{INTRODUCCIÓN ${ }^{1}$}

La inscripción ${ }^{2}$ (fig. 1) que analizaremos a continuación se conserva en la catedral de Sevilla y ha

1 Este artículo es resultado de un estudio más amplio que llevamos realizando desde hace algunos años sobre la problemática que plantean determinados textos epigráficos que se incluyen en un arco cronológico entre los siglos $\mathrm{V}$ y X. Una primera aproximación al tema fue presentada en el $I I I$ Encuentro Internacional Hispania en la Antigüedad Tardía. Santos, obispos y reliquias (Alcalá de Henares, 13 al 16 de octubre de 1998). Para la localización de algunos estudios indispensables para nuestro trabajo fue de gran ayuda la colaboración de M. Vallejo y T. Schumacher. Algunas de las fotos son de J. Beltrán Fortes, a quien agradecemos especialmente sus gestiones para poder acceder a la pieza y su generosidad en acompañarnos en la autopsia de la misma. Las conversaciones mantenidas con L.A. García Moreno previas a la presentación del trabajo han sido muy enriquecedoras, pues nos han permitido reflexionar sobre aspectos que no habíamos tenido en cuenta. Sirvan estas palabras para agradecerle además su ayuda en la obtención de algunos documentos. Igualmente somos deudoras de A.U. Stylow y L. Caballero por sus comentarios, sugerencias e intercambio de pareceres. Si quid erravimus, a culpa absunt. 154. sido atribuida al obispo Honorato, sucesor de Isidoro, pues, pese a que no se menciona en la misma el nombre del obispo, todos sus datos cronológicos apuntan a que sea dicho obispo, conocido por su

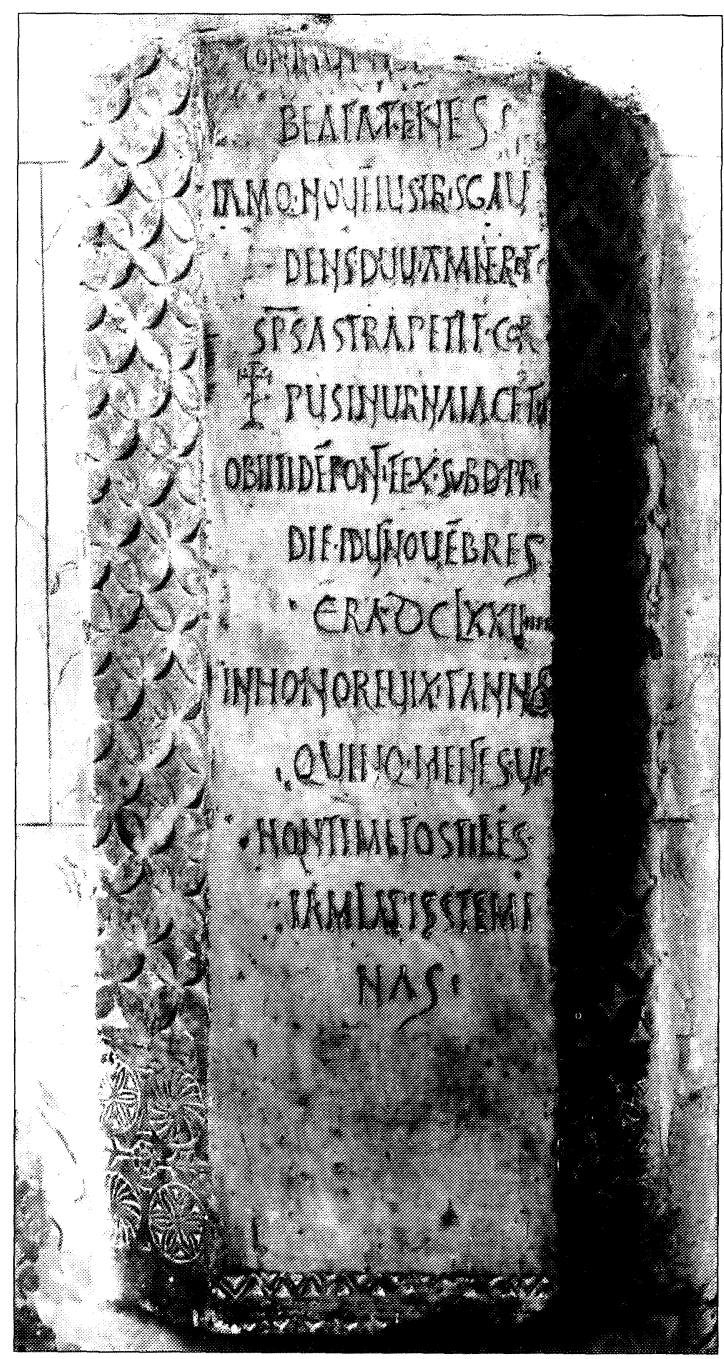

Fig. 1.-IHC 65 (Sevilla. Catedral; neg. IAA Madrid). 


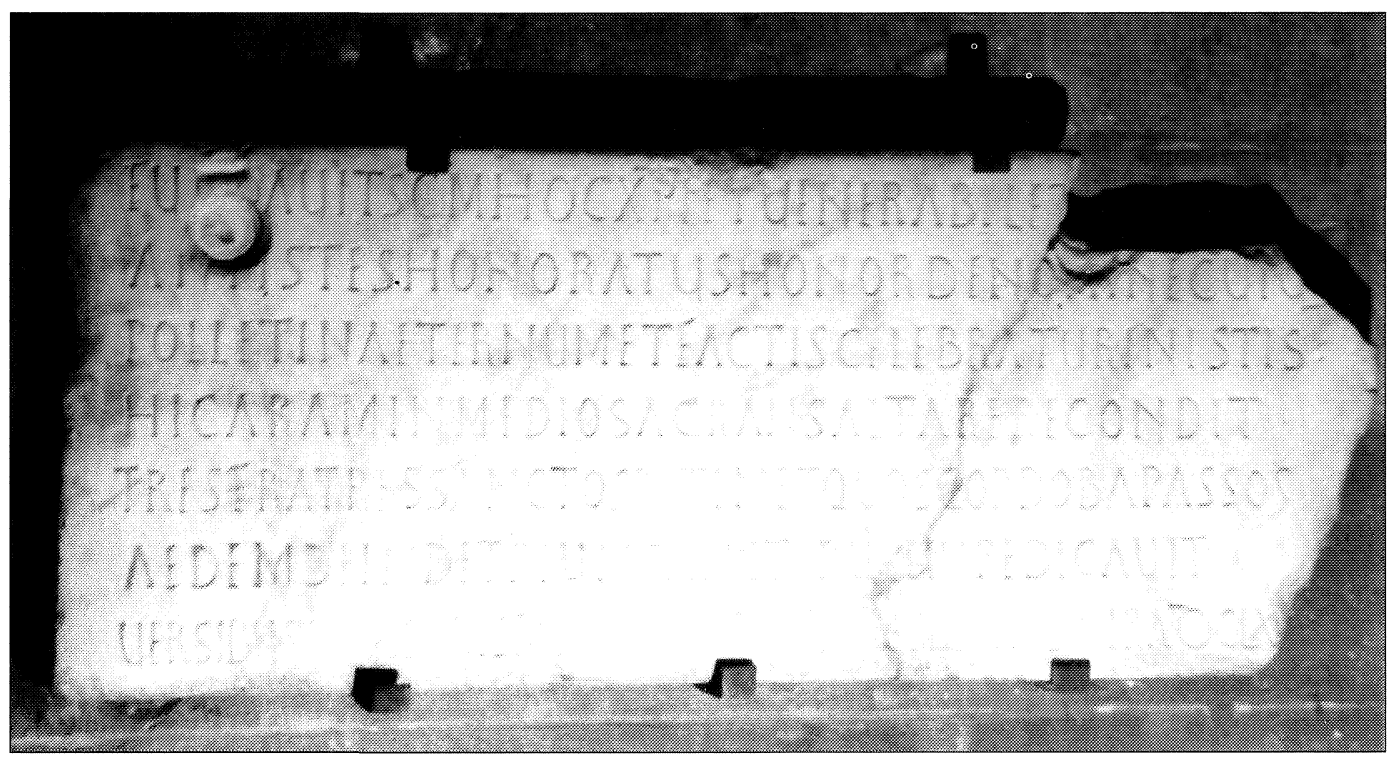

Fig. 2.-IHC 363 (Dos Hermanas; Sevilla).

suscripción en el VI Concilio de Toledo del año 638 y porque aparece en la lista episcopal del Códice Emilianense ${ }^{3}$, folio $360 v$, inmediatamente después de Isidoro. En cambio, otra tradición apócrifa, que remonta a Lucas de Tuy, conocido por el Tudense, del siglo xII, y rechazada definitivamente por Fló$\mathrm{rez}^{4}$, hace de un hereje llamado Teodisclo el sucesor de Isidoro.

$\mathrm{Si}$ es indudable, por las fuentes literarias, que el sucesor de Isidoro fue Honorato ${ }^{5}$, las fuentes epigráficas de las que disponemos sobre el mismo personaje - además de la de Sevilla, una placa de Dos Hermanas (Sevilla, fig. 2) ${ }^{6}$ - no permiten, por sus características, como veremos a lo largo de este trabajo, utilizar los datos que contienen para la biografía del obispo Honorato. Lo impide en la de Sevilla toda la problemática que plantea el titulus objeto de este estudio; y en la de Dos Hermanas, la rotura justo en la mención de la era, que ha obligado a fecharla a partir de los datos cronológicos proporcionados por la primera inscripción. Ésta presenta una serie de problemas e incoherencias que suscitan grandes interrogantes que analizaremos y expondremos en los siguientes apartados: I Soporte. - II Paleografía y ordinatio. - III Texto. - IV Hallazgo, circunstancias histórico-culturales y trayectoria de la pieza: otro carmen de Honoratus. - V Reinterpretación del titulus.

\footnotetext{
${ }^{3}$ Real Biblioteca del Monasterio del Escorial, ms. d.I.1., f. $360 \mathrm{v}$.

4 Flórez 1860: 239-241.

5 Cf. García Moreno 1974: 95, nº 180.

${ }^{6}$ IHC 363; ICERV 313; CILA II 2, 606
}

\section{SOPORTE}

Se trata de un bloque poliédrico de ocho caras, de mármol blanco, roto por la parte superior. Mide $128 \times 63 \times 18 \mathrm{~cm}$. Campo epigráfico $99,5 \times 35,5$ $\mathrm{cm}$. La cara frontal, la que contiene el texto, es más estrecha que la cara posterior, su paralela, hoy adosada a la pared, por lo que resulta imposible comprobar su estado actual. Es desde la cara frontal desde la que partiremos para describir las restantes. Ignoramos cómo remataba la cara superior, pues está rota $-\mathrm{y}$ rota ha estado desde que se publicó su texto en el siglo $\mathrm{XVII}^{7}$-, pero probablemente era como la inferior, es decir, paralela al plano. Las cuatro caras laterales, iguales dos a dos, se desarrollan de la siguiente forma a partir de la frontal: a continuación de esta última y a ambos lados igual, hay dos caras en vertiente, seguidas por otras dos rectas perpendiculares a la cara posterior.

La cara frontal, pulida, en la parte superior y abarcando la extensión más o menos de las tres primeras líneas presenta huellas de herramienta (fig. 3 ), que probablemente responden a una utilización del soporte anterior a la grabación del texto. En la parte inferior hay un festón en zigzag (que, como sabemos por una foto antigua, en su origen era doble; fig. 4) que en medio tiene una línea ondulada. La cara inferior está simplemente desbastada. Las caras laterales inmediatamente siguientes a la frontal, rotas a distinta altura, en mayor medida la dere-

\footnotetext{
7 Véase infra p. 250 el texto de Rodrigo Caro y de Fernández Bertrán referente al hallazgo.
} 


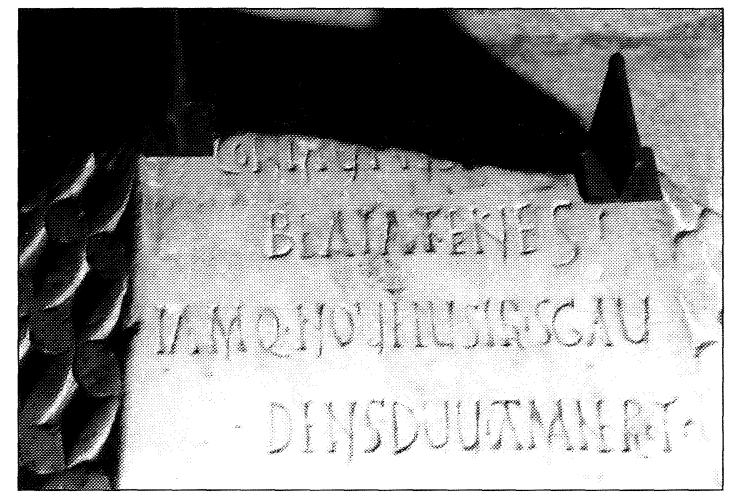

Fig. 3.-IHC 65, líneas 1-4. en Casa Herrera ${ }^{8}$, que nos llevan hacia una cronología del 500, sorprende, por su superficialidad en el grabado, la ejecución de los círculos incisos contrapuestos de la parte inferior, para los que no podemos establecer ninguna cronología precisa.

Desde el punto de vista decorativo, para las cuadrifolias un paralelo muy cercano por el lugar del hallazgo (Alcalá del Río) es la inscripción de Gregorio ${ }^{9}$, fechada en el 544 , que presenta este motivo en la cabecera, a ambos lados del crismón.

El zigzag (fig. 7) que remata la pieza por la parte inferior aparece sobre todo en la cerámica y en los ladrillos visigodos. Para el resto de la decoración, el motivo de remolino y las estrellas de seis

cha, presentan una decoración en bajorrelieve de talla plana, a base de círculos, los cuales, por medio del rebaje, forman cuartos de círculo tangentes; de todo ello resulta una red de cuadrifolias dispuestas en doble cenefa (fig. 5). Hay que destacar, sin embargo, que, en el lado izquierdo, el diámetro de los círculos es mayor que en el lado derecho, por lo que el número de círculos varía y la decoración resulta asimétrica (11 hiladas de flores en la cara izquierda; 12 en la derecha). El final de esta decoración de círculos viene a coincidir con la última línea del texto de la cara frontal. Debajo de estas cenefas, y separada de la decoración anterior por un listel, empieza otra área decorada con incisión (fig. 6). Se trata de cuatro círculos muy superficialmente incisos, contrapuestos los de similar decoración dos a dos: así, dos con el motivo de remolino y otros dos con estrella de seis puntas. Separando los pares de círculos en sentido horizontal hay una flor octopétala de inci-

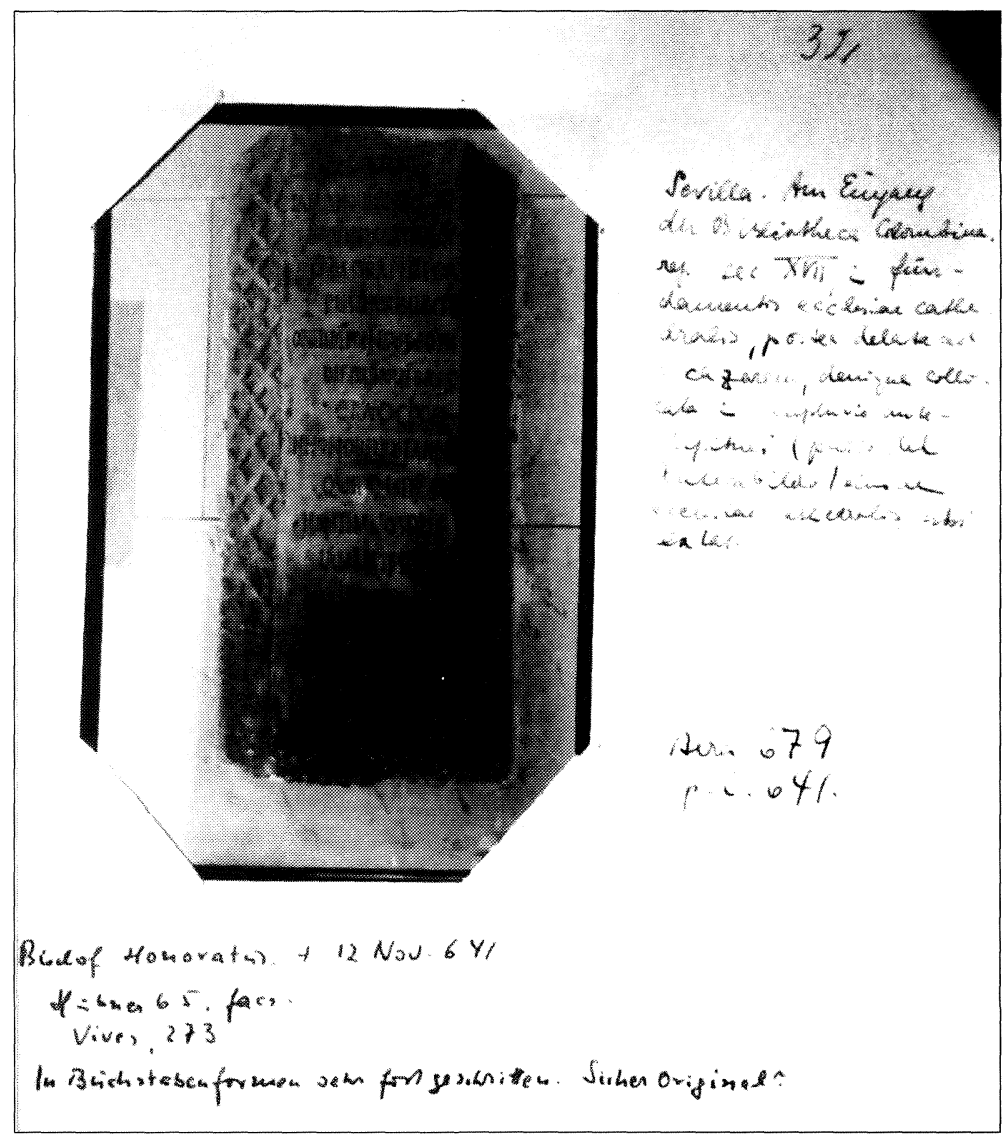

Fig. 4.-IHC 65. Decoración de doble zigzag (foto fondo H. Schlunk). sión más profunda, de la que salen dos ramas en talla plana y, en sentido vertical, unos husillos muy poco marcados. De este modo se combina técnicamente la simple incisión con el bajorrelieve. Las caras que vienen a continuación están toscamente trabajadas.

Si bien para la técnica de las cenefas con cuadrifolias, en talla plana, se pueden encontrar paralelos puntas, si bien se trata de elementos tradicionalmente representados en los repertorios iconográficos de las estelas romanas, abundan especialmente en la iconografía altomedieval, como ocurre en S. Miguel

\footnotetext{
${ }^{8}$ En las piezas de Casa Herrera la decoración presenta molinillos, no cuadrifolias. Cf. Ulbert y Caballero 1976: lám. XXIV.

IHC 60; ICERV 132; ILCV 3571.
} 


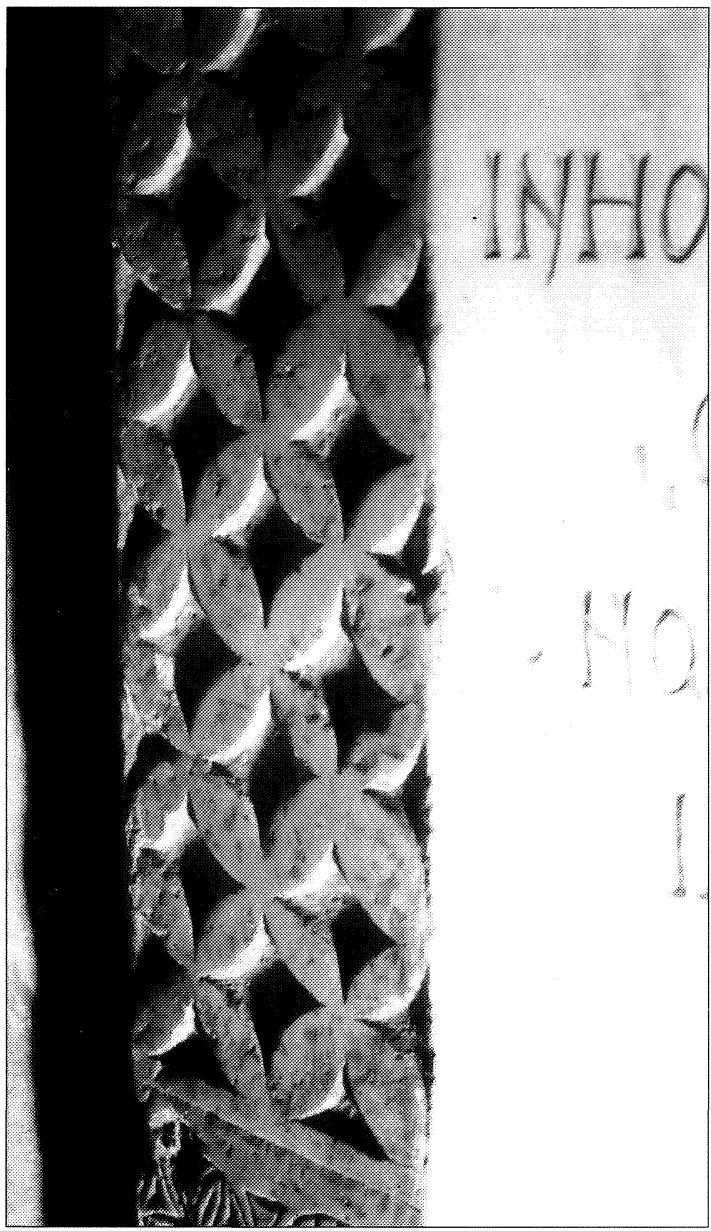

Fig. 5.-IHC 65. Decoración de cuadrifolias.

de Lillo o en S. Torcato de Guimarães, donde se combinan ambos elementos ${ }^{10}$; en cambio, resulta chocante la flor central de separación, así como la línea ondulada que se sitúa por debajo del zigzag. En definitiva, si para todos los elementos decorativos de la pieza encontramos individualmente paralelos, en su conjunto la combinación y presentación de los mismos son, sin duda alguna, insólitas.

En cuanto a la funcionalidad de la pieza, cabe decir que se ha definido como una placa, si bien por su forma ha debido tener otra función previa. El hecho de que existan huellas de reutilización en la parte superior del campo epigráfico apunta a un uso anterior de la pieza, previo a la grabación del texto. L. Caballero nos ha sugerido la posibilidad de que se trate de un cimacio de tamaño extraordinario que pudo servir para cubrir tres o cuatro capiteles juntos. De ser así, tendría sus lados oblicuos decorados

\footnotetext{
${ }^{10}$ Real 1995: 19, fig. 4; 35, fig. 33 .
}

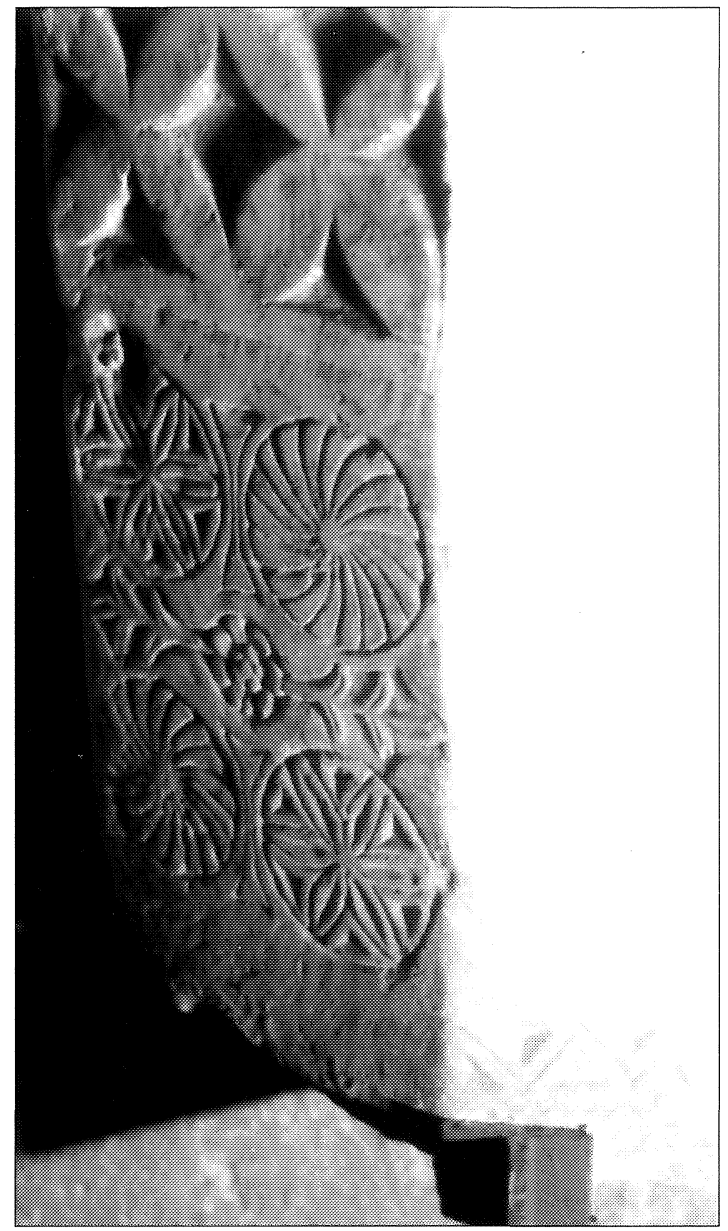

Fig. 6.-IHC 65. Decoración con círculos incisos.

con la red de cuadrifolias y estaría embutido en un muro por la parte inferior, a partir de donde termina el texto. Posteriormente esta parte inferior se decoraría con los pares de círculos incisos, para los que no tenemos los mismos paralelos cronológicos que para la técnica (hacia 500) y los motivos decorativos de la parte superior. Estos añadidos decorativos deben haber coincidido en el tiempo con la grabación del texto, que ha sido fechado, como luego veremos, por el contenido, en el siglo viI.

La pieza, más que una placa, como siempre se ha definido ${ }^{11}$, recuerda por su forma poliédrica y sus dos vertientes laterales a una tapa de sarcófago, aunque con el campo epigráfico mucho más ancho de lo que se esperaría para un sarcófago ${ }^{12}$. Identificarla

"IHC 65; ICERV 273; CILA II 2, 154; Schlunk-Hauschild 1978: 194-195, fig. 93 .

12 Así fue definida por los primeros editores de la pieza, como Caro (1627), quien la considera una tapa de sarcófago en sus Additiones, f. 233r.: ipsius Honoratiani sepulcri operculum marmoreum. 


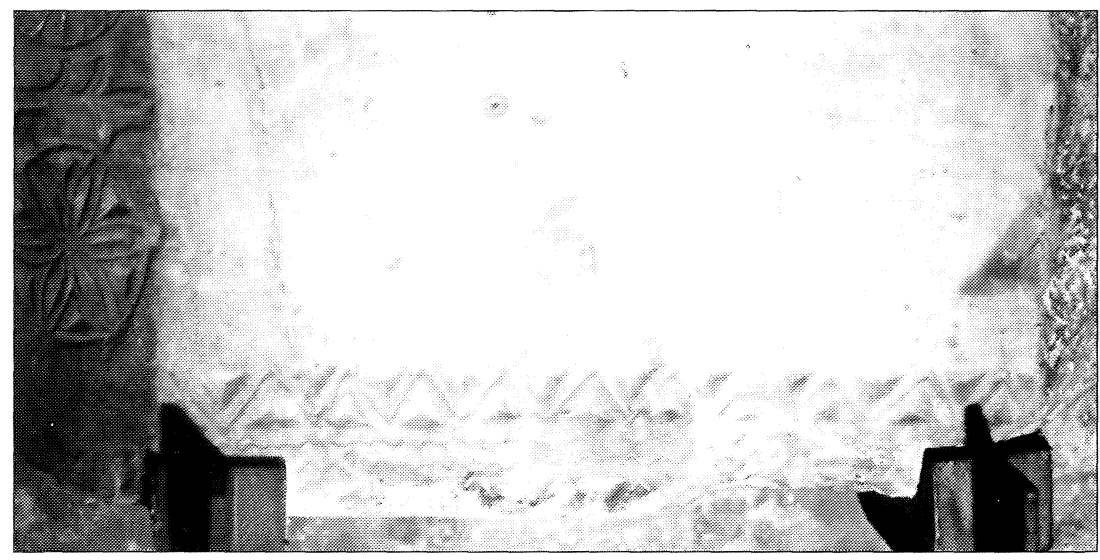

Fig. 7.-Zigzag inferior, detalle.

como tal plantea serios problemas: si bien es cierto que la altura de la pieza no se ajusta en su estado de conservación actual a las dimensiones propias de un sarcófago, el hecho de no conocer cómo remataba por la parte superior nos impide saber no sólo la cantidad de texto que falta sino también si existía o no, por encima del campo epigráfico, una superficie sin grabar similar a la que encontramos por debajo del mismo. Si así fuera, la altura total de la pieza sería adecuada para una tapa de sarcófago, aunque tapas de sepulcro con inscripción de estas características apenas se utilizaron en Hispania. Un posible paralelo se encontraría en la inscripción de Ithacius $^{13}$, de Oviedo, tampoco exenta de problemas ${ }^{14}$ pues, mientras que Hübner pensaba, a partir de la talla de las letras, no incisas sino en bajorrelieve, que no podía ser anterior al siglo Ix, a pesar de que el verso y el nombre podían corresponder tanto al siglo $\mathrm{v}$ como a los siglos VI y VII, Bücheler insistió en que el nombre y el carmen se adecuaban muy bien al siglo v. A partir de esto, el resto de los autores que han tratado sobre esta tapa han coincidido sistemáticamente en proponer una cronología de los siglos $\mathrm{V}$ o vı, incluidos Schlunk y Hauschild ${ }^{15}$, para quienes la inscripción de Ithacius resulta, pese a todo, también excepcional en muchos aspectos. Un segundo problema para que la inscripción de Honorato pueda ser considerada una tapa de sarcófago radica en el hecho de que la cara inferior no esté trabajada, pues, si fuera tapa, al estar a la vista, debería haberlo estado, como en el resto de los sarcófagos que conocemos, a no

13 IHC 144; ICERV 292; ILCV 3700; CLE 1397

14 En el repertorio de sarcófagos hispanos la cubierta de Ithacio es también insólita. Presenta, sin embargo, analogías con ejemplares del sur de las Galias y, en especial, con algunas piezas de los talleres de Rávena. Para los sarcófagos de Rávena, véase Bovini 1954 y Lawrence 1970.

15 Schlunk-Hauschild 1978: 138-139, fig. 30-31 ser que por esta cara hubiera estado adosada a un muro, hecho que parece poco posible, pues la disposición lógica del texto para ser leído hubiera sido, en tal caso, o bien escrito en sentido inverso al que ahora tiene o bien grabado horizontalmente, con líneas más largas. Está claro, pues, que lo que marca el fin de lo que se quiere hacer visible es el festón en zigzag que aparece en la parte inferior de la cara frontal. Por tanto, es difícil pensar que la pieza haya sido concebida como una tapa para reposar horizontalmente, sino más bien como una pieza para ser apoyada verticalmente sobre la cara inferior.

A pesar de haber sido definida tipológicamente como una placa, es difícil que, por su forma, grosor y por el trabajo de las caras, estuviera destinada a ser encastrada en una estructura arquitectónica o en una tumba. Las placas se incrustaban en los sepulcros que estaban construidos habitualmente en cemento o barro, o bien con ladrillos.

Por todo lo expresado es evidente que la pieza con su texto fue concebida para verse frontalmente y quizá apoyada sobre su base inferior adosada a un muro para aumentar su estabilidad, o bien empotrada hasta el inicio de las caras en vertiente decoradas. En el primer caso, podríamos pensar en una utilización como pie de altar; sin embargo, la propia forma lo desaconseja. En el segundo caso, tendría una función de simple cenotafio.

\section{PALEOGRAFÍA Y ORDINATIO}

Las letras, aunque de incisión bastante profunda, a primera vista no resultan extrañas a la escritura propia del siglo VII, pero los mismos tipos los encontramos también en la letra capital de siglos posteriores (VIII, IX y X), documentada tanto en piedra como en 


\section{EXPLET DRAGNTIILBERPRIMVS}

\author{
orfóaricamundo. -

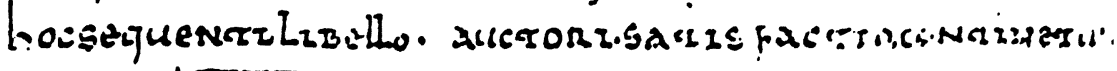

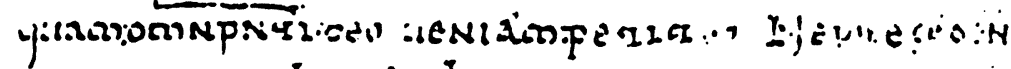

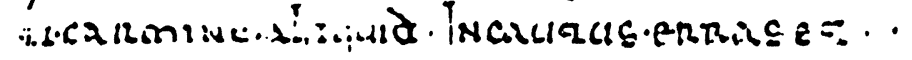

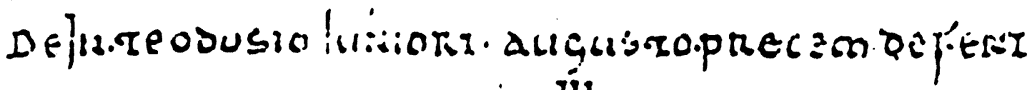 \\ LEEPITLIBERSCDS: DRACOMIT:
}
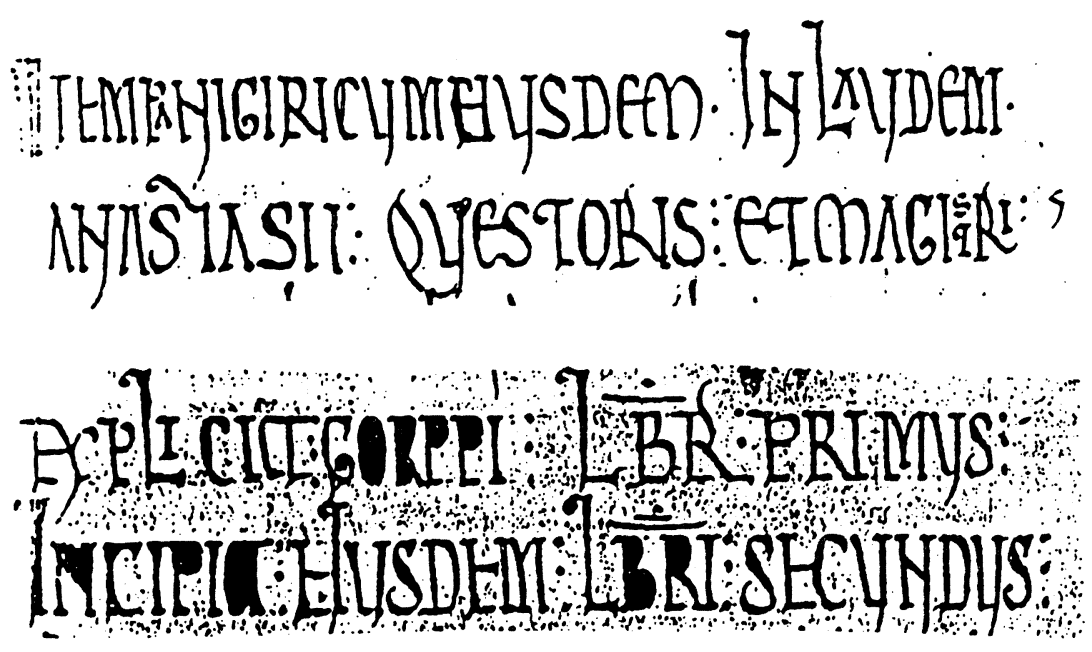

Fíg. 8.-Códice de Azagra, folios 12, 20 y 28.

tal de las $\mathrm{T}$ es ascendente de izquierda a derecha. Pero sobre todo llama la atención la abundancia de nexos, a veces de formas muy curiosas como VS en idus (1. 8), OS en annos (1. 10), o NS en menses (1. 11), o también algunas líneas que no forman nexos pero unen letras, como en honore (1. 9), donde $\mathrm{HO}$ están unidas por un trazo horizontal, fenómeno que también constatamos en la inscripción de Trevélez en 1.4 entre la VS de Floresindus.

A pesar de que la paleografía, en la forma, no discrepa en su aspecto general - y en su conjunto- de otros epígrafes del siglo vil, sin embargo sí es clara la discordancia que presenta respecto a, precisamente, el epígrafe ya mencionado de Dos Hermanas (Sevilla), de un antistes Honoratus, atribuido al mismo personaje. Esta última inscripción, no sólo por su calidad en la incisión sino por la armonía en todo su

códices (véanse especialmente las B, E o R del f. 12; E, M, N y de los ff. 20 y 28 del códice de Azagra, fig. 8). Una característica común a la escritura de la inscripción de Honorato consiste en la exageración de los rasgos: así, destacan algunas M cuyo ángulo central se prolonga hacia abajo en una especie de rabo (1. $1,11)$, como ocurre también con el segundo trazo vertical de las $\mathrm{N}$ y de las $\mathrm{U}$. Si bien es verdad que estos apéndices son relativamente habituales para las $\mathrm{U}$ o las $\mathrm{N}$ en el siglo vil, en el caso de las $\mathrm{M}$ se han exagerado especialmente. Con este apéndice prolongado la encontramos en inscripciones a partir del siglo vIII, como en una de Trevélez (Granada, fig. 9) fechada entre los años 852 y $886^{16}$. Hay $S$ que presentan las dos panzas y la cola del trazo inferior muy prolongado, pero otras son totalmente verticales, como las que conforman nexos en idus (1. 8) o en menses (1. 11), tal y como aparecen también en la inscripción mozárabe de Trevélez en 1. 3, 4 y 6. El trazo horizon- conjunto resulta muy distinta y, desde luego, es evidente que se ha seguido un modelo o una minuta para su elaboración, mientras que esta pauta no se ha mantenido en la inscripción que nos ocupa. En la inscripción de Dos Hermanas la letra es uniforme, el espacio está compensado, tanto en las líneas como en los espacios interlineales, a diferencia de la de Sevilla, en donde en general la grabación está muy descuidada: letras de tipos distintos, líneas que empiezan a una altura y se graban saliéndose de la caja con que se inician, etc. No deja de ser curiosa también la disposición de la última línea, en la cual la terminación -nas (de minas) aparece prácticamente centrada respecto a la caja del texto.

A lo largo de la inscripción existen dos tipos de interpunción. Por un lado, triángulos con el vértice hacia abajo tienen como misión separar palabras y,

${ }^{16}$ IHC 454 (= IHC 292). 


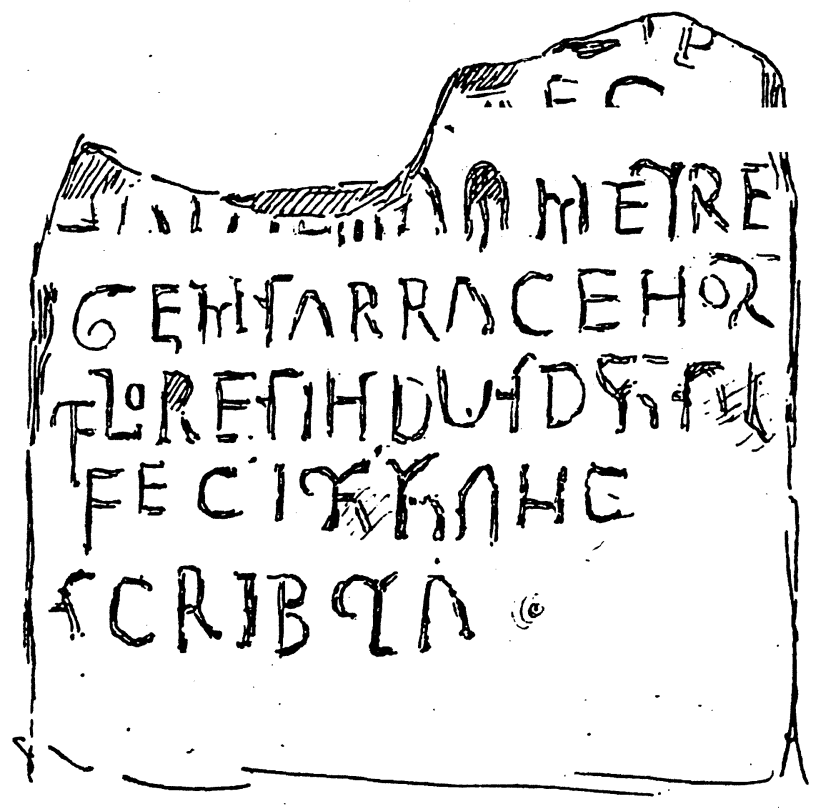

Fig. 9.-IHC 454 (Trevélez; Granada).

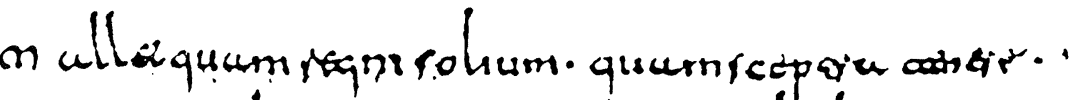
ecminur Impors a ruaninguarion Inchar conrois. Lebua er amunum foroon. prearar dolebua.'

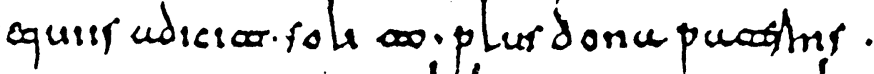

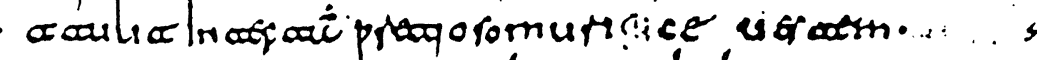

1)

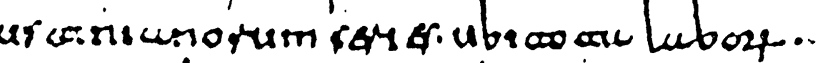

T. conoto ins curouts cuftefu cgresce fulumse

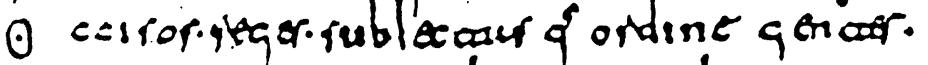
$s$

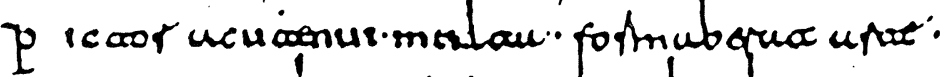

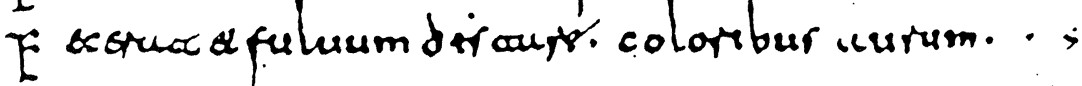

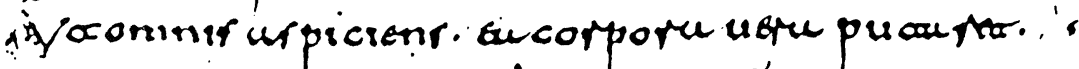
L fficior unsiorungener. deping gour of oro.

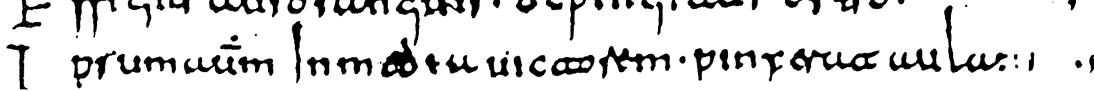

Fig. 10.-Códice de Azagra, folio $26 \mathrm{v}$. 
por otro lado, una interpunción en forma de coma al final de las líneas sirve en este caso para marcar el final de secuencias métricas. Este último tipo de interpunción aparece también en los códices, al final de las líneas (véase cod. Azagra f. 26 v., fig. 10).

Existen finalmente grafitos más recientes, como la cruz a la altura de la 1. 6, que, en cualquier caso, tiene que ser posterior a principios del siglo XIX, porque no aparece en un dibujo (Biblioteca Colombina, Sevilla, sign. 84-4-7) de F.X. Delgado de 1822 (fig. 11), y anterior a Hübner, que ya la vio.

Respecto a la ordinatio, el texto guarda cierta alineación vertical en el margen derecho, mientras que, en el izquierdo, se sangran las líneas a distinta altura. La sangría es, en efecto, relativamente frecuente en las inscripciones, bien como mero recurso decorativo, bien, en los carmina epigraphica, como delimitación de la unidad métrica, especialmente en el pentámetro del dístico elegíaco. En cambio, aquí, también un carmen, con este recurso se separan unidades de sentido que se corresponden con los tres párrafos que relatan los momentos de la vida del personaje que se quieren resaltar (no consideraremos las dos primeras líneas, puesto que nos faltan por arriba).

\section{TEXTO}

\author{
conmuni se[de] \\ beata tenes, \\ iamq (ue) $\cdot$ nove $(m)$ lustris gau- \\ dens $\cdot d u(m)$ vitâ mâneret, \\ 5 sp(iritu)s astra petit cor- \\ pus in urna iacet. \\ obiit ide $(m)$ pontifex $\cdot$ sub d(ie) pri- \\ die.idus Nove $(m)$ bres \\ era DCLXXVIIII \\ 10 in honore vixit annos \\ quinq(ue) $\cdot$ menses $\cdot V I$. \\ non timet ostiles. \\ iam lapis (i)ste mi- \\ nas,
}

Se trata de un carmen funerarium aparentemente polimétrico ${ }^{17}$ pero muy probablemente concebido en dísticos elegíacos, tal como veremos a continuación.

El texto se distribuía en cuatro párrafos de los que, enteros, sólo quedan tres. El primero, que debería de contener al principio el nombre del difun-

\footnotetext{
${ }^{17}$ Así se define en Colafrancesco 1986: 110.
}

to, acaba con una alusión al reino de los cielos, un eco del reino feliz virgiliano que el difunto ya posee ${ }^{18}$. La parte visible, por lo menos parcialmente, corresponde al pentámetro del primer dístico, al que, como hemos dicho, falta el hexámetro.

El segundo párrafo, que contiene el segundo dístico, sin problemas métricos, narraría el tiempo que ha vivido el personaje, aunque la presencia del adverbio iam como refuerzo de la conjunción dum resulta semánticamente extraña, pues aludiría a un momento temporal posterior a la defunción que se contradiría con la idea durativa expresada por la cláusula dum vita maneret. Estas interpretaciones aparentemente contradictorias son igualmente viables en la medida en que la incorrección sintáctica de los períodos de este dístico deja una gran libertad interpretativa, por lo menos en el plano lingüístico. En efecto, la conocida cláusula virgiliana $d u m$ vita maneret ${ }^{19}$, que debería servir para contextualizar alguna actividad o mérito del personaje en vida, no encaja en absoluto ni con el texto que le precede (iamque nouem lustris gaudens, sin duda la expresión de la edad del difunto) ni con el texto que le sigue (spiritus astra petit, corpus in urna iacet, una clara alusión al momento de su defunción y deposición). Probablemente el sentido del texto sería que vivió durante nueve lustros hasta que su espíritu alcanzó los astros y su cuerpo descansó en la urna ${ }^{20}$. La oposición que en los versos 5 y 6 se establece entre spiritus y corpus corresponde a un tópico bien documentado, ya presente en los carmina paganos y que arranca de la tradición platónica y pitagórica.

${ }_{18}$ Aen. 6, 639: fortunatorum nemorum sedesque beatas.

19 Aen. 5, 728.

20 Tal incongruencia sintáctica surgida tanto de la anteposición del adverbio iam (que sin duda va referido a los verbos petit y iacet) como del extraño uso del participio de presente gaudens (cuando sería más correcto gramaticalmente un participio de perfecto que expresara anterioridad) dificulta sobremanera la comprensión, y permite otras interpretaciones, como refleja la traducción que CILA II 2, 154 ofrece del dístico: «hace ya nueve lustros que tu alma, alegre mientras la vida perduraba, buscó el cielo». No se entiende demasiado bien que la muerte se haya producido 45 años antes, por lo que petit, como iacet, debe ser un presente. Precisamente, a raíz de esta dificultad interpretativa surgió una polémica tras nuestra comunicación presentada en el III Encuentro Internacional Hispania en la Antigüedad Tardía. Santos, obispos y reliquias (Alcalá de Henares, 13 al 16 de octubre de 1998) y se nos sugirió que contemplásemos la posibilidad de una translatio de los restos del obispo en época mozárabe. En este caso habría dos momentos cronológicos en el texto, marcados respectivamente por el verbo petit (pasado, momento de la defunción) y tenet (presente, momento de la translatio), explicación que nos parece sin embargo muy forzada al considerar sobre todo la gran frecuencia del recurso a este tópico para aludir simplemente a las virtudes o defectos del difunto o a su edad, como en este caso. 
Jacques Fontaine ${ }^{21}$ habla de «catasterismós cristiano» para referirse a la metáfora astral expresada en spiritus astra petit, fórmula que constituirá también uno de los clichés predilectos en epitafios medievales y renacentistas. Sorprende la utilización del término urna, ya que ésta, por definición, es un vaso que continet ossa o cineres, por lo cual resulta extraño (y sin paralelos, por lo menos que nosotras conozcamos) que este término se aplique a una pieza que a todas luces no lo es. Por las características del titulus, menciones del tipo tumulus, sepulc(h)rum, o simplemente expresiones como hic cubat, hic iacet, in pace requiescit, hic situs est hubieran sido más adecuadas.

El tercer párrafo puede considerarse un pseudosubscriptum totalmente prosaico que recoge una serie de precisiones cronológicas: el día de la muerte del personaje y la duración de su pontificado. Resulta muy curioso que estos datos no se consignen al final o al principio del carmen, sino insertos en el texto. Por otro lado, el texto en prosa no está exento de rarezas morfológicas, como la presencia del demostrativo anafórico de identidad idem, que, además de resultar pleonástico, no presenta demasiados usos en la epigrafía tardía hispánica. La insistencia en la identidad del obispo no se justifica, pues no parece que se mencione en el carmen ningún

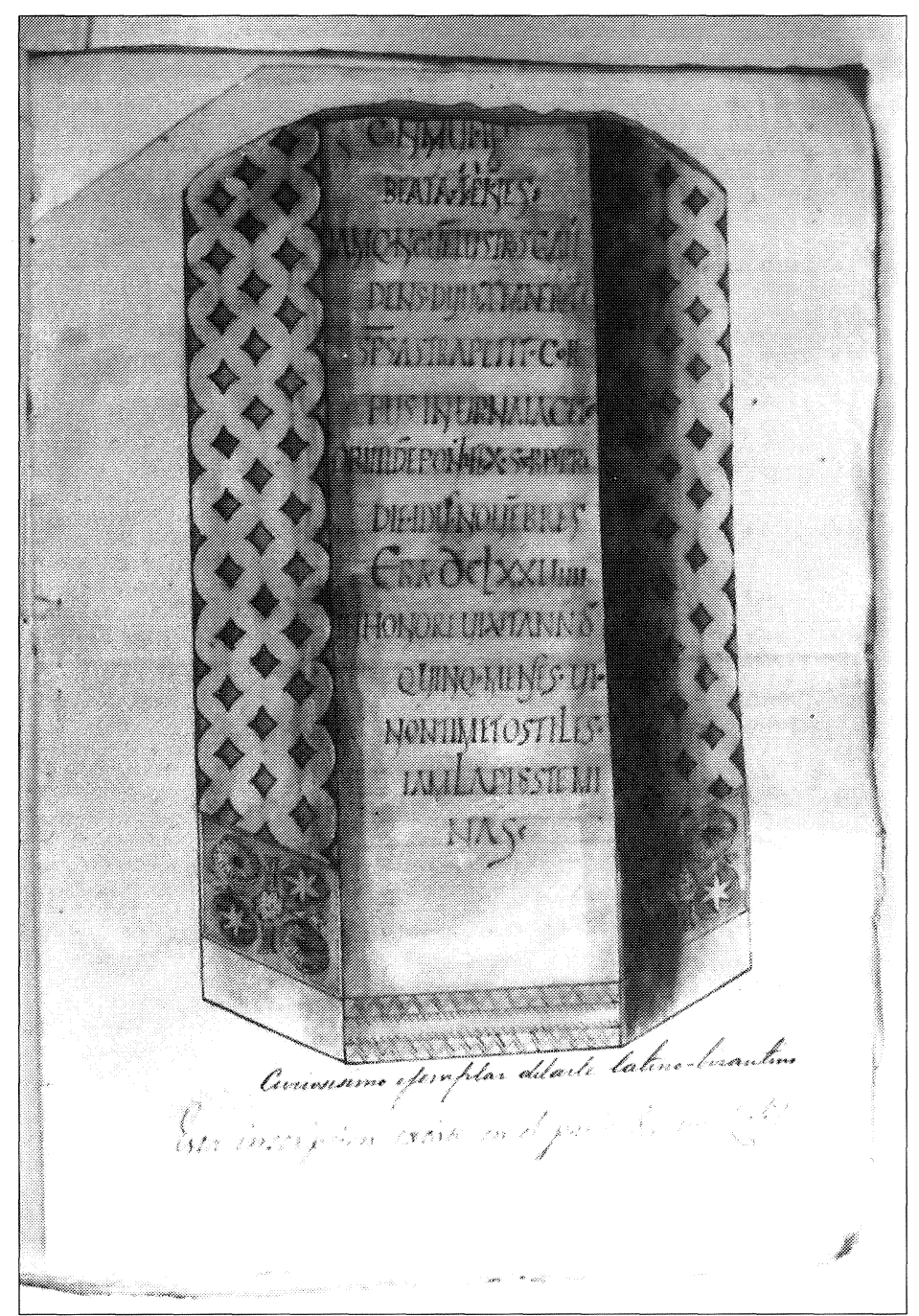

Fig. 11.-IHC 65. Dibujo de F. X. Delgado, año 1822. otro personaje con quien pueda confundirse. La fórmula de datación sub die pridie, aunque incorrecta en la lengua clásica, tiene paralelos en la epigrafía cristiana de Hispania, tanto para el uso no normativo de la preposición $s u b^{22}$, como para el pleonasmo die pridie, en el que el adverbio funciona prácticamente como un ordinal ${ }^{23}$. Por lo demás, la interpretación tradicional de la fórmula in honore como un juego paranomásico con el nombre del obispo, como ocurre en la inscripción de Dos Hermanas, no puede descartarse, pero tampoco es segura.

Sigue al subscriptum un cuarto párrafo constituido por un pentámetro al que obviamente falta el

\footnotetext{
${ }^{21}$ Fontaine 1959 (vol. 2): 560.

22 ICERV 32, 42, 44, 54, etc.

${ }_{23}$ ICERV 68, 302.
}

hexámetro: non timet ostiles iam lapis (i)ste minas, verso tomado de Marcial ${ }^{24}$. Al margen de su contenido y de la ausencia del hexámetro correspondiente, la principal particularidad de este verso radica en la posible aféresis del demostrativo iste, favorecida por haplografía, y justificada por ultracorrección, a pesar de la cual la $i$ se computa métricamente, sin descartar tampoco la posibilidad de que se trate de un simple olvido del lapicida. Sin duda, lo más enigmático de este verso es su significado, pues no parece que se aluda aquí a una posible violación del sepulcro. En definitiva, nos hallamos ante una com-

${ }^{24}$ 6, 76, 4: Ille sacri lateris custos Martisque togati, / credita cui summi castra fuere ducis, / hic situs est Fuscus. Licet hoc, Fortuna, fateri: / non timet hostilis iam lapis iste minas; / grande iugum domita Dacus ceruice recepit / et famulum uictrix possidet umbra nemus. 
posición de carácter casi centonario con notables rarezas que afectan tanto a la exposición coherente del contenido como a la forma en que éste se presenta. Es un epigrama híbrido, pues no se trata ni de un elogio ni de un simple epitafio, sino de un intento de ennoblecer al personaje a través de una sucesión de datos biográficos.

\section{HALLAZGO, CIRCUNSTANCIAS HISTÓRICO-CULTURALES Y TRAYECTORIA DE LA PIEZA: OTRO CARMEN DE HONORATUS}

Las noticias acerca del hallazgo de la inscripción de Sevilla son bastante confusas y aún más sus sucesivos traslados. El primero que menciona la existencia de la inscripción es Rodrigo Caro en su edición del año 1627 de la Chronica de Flavio Lucio Dextro ${ }^{25}$, que incluye al final unas Additiones ${ }^{26}$ que contienen los fragmentos de la crónica de Máximo, de Heleca y de S. Braulio, así como unas composiciones en verso, entre las cuales se encuentra un epitafio escrito por Taio Caesaraugustanus archidiaconus dedicado a Honoratus germanus suus Caesaraugustanus, archiepiscopus Hispalensis sanctissimus pontifex.

Precisamente el epitafio ${ }^{27}$ aludido, conservado en los folios 232v. y 233r., es el siguiente:

Praesul Honoratus successerat hic Isidoro,

Hispalis illius ossa beata tenet.

Iamque noven lústris gaude(n)s, dum vita maneret,

5 Spiritus astra tenet, corpus in urna iacet.

Vita fuit melior lingua, sed lingua modesta,

Nunc ovat, hostiles nec timet ille minas.

${ }^{25}$ Flavii Lucii Dextri V.C. Omnimodae Historiae quae exta(n)t fragmenta cum Chronico $M$. Maximi et Helecae ac S. Braulionis Caesaraugustanorum episcoporum notis Roderici Cari Baetici illustrata anno. MDCXXVII Hispali apud Mathiam Clavigium. La elaboración de la obra por Román de la Higuera fue lenta y por ello circuló en un primer momento en copias manuscritas, objeto de numerosas interpolaciones. La primera edición se debe a fray Juan Calderón, de la orden de los Menores, que hizo imprimir, según una de las copias, el texto, el cual apareció en Zaragoza en 1619.

26 Ofrecemos la traducción castellana del texto de Caro. En latín lo mantenemos en nota.

${ }^{27}$ Hübner lo da como falso en $I H C 16^{*}$ y lo toma de Tamayo, indicando que está compuesto a partir de la de Sevi1la. Señalemos también que en 1627 , precisamente el mismo año de la publicación de las Additiones de Rodrigo Caro, aparece una edición, a cargo de Ramírez de Prado, del llamado Chronicon de Pseudo-Juliano, cuyo núm. 414 alude también al carmen Taionis.
Obiit idem Pontifex pridie idus Novembris, aera DCIXXIX. in honore vixit annis quinque mensibus sex.

Después añade Caro: La tapa marmórea del sepulcro del propio Honorato estuvo durante mucho tiempo en Sevilla yaciendo entre los materiales de derribo de unos edificios, hasta que el ilustrísimo señor Benedicto Arias Montano ${ }^{28}$, cultivador de las artes de Minerva y amante de toda la Antigüedad, se la llevó a su casa extrayéndola de entre los escombros, pero, nuevamente manchada por el olvido con el paso destructor del tiempo, Juan de Torres Alarcón, sevillano, de profesión teólogo y un ferviente recuperador de antigüedades, la condujo de nuevo a su bien fornida biblioteca, y allí, entre un gran surtido de códices antiguos, de volúmenes escogidos, de monedas y diplomas y otros ilustres documentos, que según se dice había recogido con gran gasto por su parte para la historia de su patria, la conserva, para que todos la vean y la lean. Los dos primeros versos (en el texto carmina) del epigrama desaparecieron al estar rota la piedra. Sin embargo tiene conservadas estas letras que yo, fielmente, he copiado ${ }^{29}$.

28 Refiriéndose a su postura ante la falsificación de los plomos del Sacromonte, dice Godoy Alcántara (1981: 107 108) que por indicación del rey llamó el arzobispo a Arias Montano, que residía en Sevilla. Excusóse de ir el afamado sabio alegando sus padecimientos, pero le recomendó gran prudencia y detenimiento, poniéndole delante los daños que resoluciones precipitadas en tales asuntos acarreaban a la Iglesia: El vulgo, le decía, (y Dios sabe dónde el límite del vulgo se detenía), el vulgo, amigo de novedades y materias de conversación, desea se autoricen tales cosas, más por tener que hablar que por mejorar su vida. Arias Montano, retirado de la vida activa y cansado de polémicas, si bien privadamente manifestaba su opinión conforme con la de los impugnadores, rehusó siempre tomar parte en pro o en contra, no bastando a sacarle de su neutralidad las vivas excitaciones que para atraérsele de uno y otro lado le dirigían. Así, pues, en el caso que nos ocupa, que una autoridad como Arias Montano legitime la autenticidad de la inscripción que en su casa se guardaba reviste, sin duda, una gran importancia. Arias Montano había muerto en 1598. Román de la Higuera tenía, pues, el terreno despejado para sus invenciones. Hablando Godoy (1981: 131-132, nota 1) de la Historia eclesiástica de España escrita por Higuera, a lo que parece no editada, señala cómo también utiliza la autoridad de Antonio Agustín para legitimar la absolución de Atanasio, hecho que, según Higuera, ya relata Antonio Agustín en la Historia de los Concilios que nunca se imprimió

${ }^{29}$ Ipsius Honoratiani sepulcri operculum marmoreum Hispali diu inter abiecta aedificiorum rudera in glorium iacuit donec vir clarissimus Benedictus Arias Montanus, sacrae cultor Minervae et totius antiquitatis amator; ab illo squalore erutum domum transtulit, sed succedente temporis iniuria, iterum oblivione iam sordidum, Ioannes de Torres Alarcon Hispalensis, professione Theologus, diligens antiquitatis coquisitor; ad suam instructissimam Bibliothecam 
Tras lo cual transcribe Rodrigo Caro (233r.) el epitafio conservado en piedra con el texto que ya conocemos.

En cuanto al carmen atribuido a Tajón, hay que señalar primero que no se conserva en ninguna de sus obras, segundo que ninguna otra fuente menciona a Tajón como hermano de Honorato y, por último, que existen diferencias entre el epigrama atribuido a Tajón y la inscripción en piedra conservada, como ya constató Nicolás Antonio en una carta ${ }^{30}$ dirigida a Martín Vázquez Siruela fechada en 16 de julio de 1658 y especificó también en su Bibliotheca Hispana Vetus ${ }^{31}$. Basta cotejar el carmen ${ }^{32}$ introductorio a los cinco libros de Sententiae que escribió Tajón con el que se le quiso atribuir, para percatarse no sólo de las divergencias estilísticas sino también del distinto dominio del nivel lingüístico.

Comparando los dos textos de Honorato, el poema atribuido a Tajón está completo, con mención explícita en el primer hexámetro de Honorato como sucesor de Isidoro. Le sigue un pentámetro, en el que se alude a la ciudad que conserva sus ossa beata, Hispalis. Por otra parte, el uso del demostrativo illius es propio sobre todo de los primeros estadios romances. Sí coinciden plenamente ambos textos en el hexámetro siguiente, verso 3 del carmen de Tajón. En cambio, en el verso 4, la presencia de tenet contrasta con el verbo petit que se lee claramente en la piedra. El hexámetro del último dístico, que falta en la piedra, vita fuit melior lingua, sed lingua modesta, es un extraño tópico que parece aludir a la excelencia de vida del difunto y a su modesta elo-

iterum reduxit, ibique inter magnam Codicum antiquorum, Selectorum voluminum, numismatum, diplomatumq: suppellectilem, aliaq: illustria monumenta, quae ad historiam suae patria ait magno sumptu comparasse, omnibus videndum, legendumq; conservat. Prima duo epigrammatis carmina, divulso lapide, perierunt: has tamen litteras, quas ego fideliter exscripsi, superstites habet.

${ }^{30}$ Palacio Real ms. II 158 f. 103 v.: Igual duda me hace el hallarse en Taio cesaraugustano el epitafio de nuestro arzobispo de Sevilla Honorato casi en la misma forma que se lee en la piedra que se guarda, según me dizen, en la antesala de ese cabildo: cuio descubrimiento se refiere ser más moderno que la formación de estos apéndices a la Crónica de Dextro y Máximo.

${ }_{31}$ Véase nota 46, Bibliotheca Hispana Vetus, t. I, p. 424, c. 721: Huius carmen in sepulcro...

${ }^{32}$ Quisquis amas sacram lector addiscere legem, / Hunc nostri studii librum percurre legendo: / Repperies facile quidquid congnoscere malis. / Florea cuncta gerit [tum] prata virentia gestat. / Pascit amantis oves sincera animalia Christi, / Ostendit patriam celsam, regnumque potentem, / Tartareos ignes, et tristia non finienda. / En tibi Christus adest regnum conferre beatis, / Impiis e contra horrenda supplicia confert. / Sublimis anima, conscende ad regia coeli; / Impiger accurre, careas ne praemia tanta; / Et picei fontis horrendas despice flammas. cuencia. Quizá quiera expresar su santidad a través de la obra más que de la palabra. En los $C L E$ no se encuentran paralelos de este símil. Por último, el subscriptum se ha colocado tras el poema, como es preceptivo, y el pentámetro ha vuelto a su sitio, aunque ahora no tenemos un locus parallelus de Marcial sino la cláusula nunc ovat, hostiles nec timet ille minas.

Tras haber copiado el texto de la inscripción añade Caro en los folios 233v. y 234r.: Así, pues, por este antiquísimo epigrama tienes un testimonio evidente de la veracidad y solidez de nuestros fragmentos, los cuales, si no se apoyaran en otro lugar, por sí mismos (ya) alejarían (amoveret quizá por amoverent, sin marca de abreviatura; de no ser así el texto no se entiende) cualquier tipo de sospecha de impostura, y los justos peritos de la antigüedad sabrán juzgar en cuánto hay que valorarlos. Gracias a él (a este testimonio) alejaremos definitivamente la injuria causada a la santa iglesia hispalense suffecto Theodisclo, Sanctissimo Praesuli Isidoro (quizá signifique reemplazado Teodisclo ${ }^{33}$, al santísimo obispo Isidoro, es decir, eliminando a Teodisclo como sucesor del santo obispo Isidoro, aunque la sintaxis es muy extraña). Y aunque los autores hispanos y extranjeros discrepen entre sí acerca del año de la muerte de Isidoro, atribuyo, tras un cálculo segurísimo, que acaeció en el año 636 d.C., que cayó, como es de esperar, en la era 674. Así lo testifican Redempto, discípulo de Isidoro que estuvo presente, y el códice aquel de $\mathrm{Ni}$ colás Faber ${ }^{34}$, donde se recogen los epitafios de los santos hermanos Leandro, Isidoro y Florentina, aunque en éste, por lo que atañe al óbito de Leandro, se ha escrito incorrectamente la era 641 , cuando murió en la era 633, pero el día de la muerte de Isidoro fue la víspera de las nonas de abril, en la era 674. Además, a partir del mismo Redempto se comprueba fácilmente que el año correcto de la muerte de Isidoro fue el mismo 636. En efecto, él presenta a Isidoro, cuatro días antes de morir, hablando así al pueblo: "así, como el agua de una fuente sagrada, que hoy el pueblo devoto se dispone a recibir, sea para vosotros en remisión de los pecados, y que este beso permanezca entre nosotros como testimonio de las cosas futuras. Acabadas estas acciones, se retiró a su celda: y al cuarto día después de la confesión y de la penitencia, consu-

${ }^{33}$ De él Godoy afirma (1981: 194) que fue quien motivara con su herejía la transferencia del primado a Toledo, ... (Cronicón de Luitprando, Adiciones -Adversaria-, en los que se acredita la existencia del arzobispo sevillano Teodisclo).

${ }^{34}$ Se refiere a la Anthologia Hispana. 
mó en paz su cargo pastoral y su vida. Amén. En el día anterior a las Nonas de Abril, en la luna decimonovena. Era 674.»Y si consultas los ciclos pascuales, para este año fácilmente encontrarás que la pascua cayó en la víspera de las calendas de abril, y que así el bautizo solemne de los catecúmenos acaeció cuatro días antes de la muerte de Isidoro. $Y$ hay otra razón de tal naturaleza que zanja completamente el asunto. Pues que la muerte de Isidoro sucedió el cuarto día del mes de abril es cosa segura y en esto todos están de acuerdo, pero en el segundo año del rey Chintila, es decir en el mes de enero del 637, el obispo hispalense Honorato suscribió el quinto concilio de Toledo ${ }^{35}$, de manera que ¿ya había muerto su antecesor Isidoro? Por lo tanto, como Honorato viviera en el cargo de su pontificado cinco años y seis meses, y muriera la víspera de los idus de noviembre, en la era 679, es decir, en el año 641 d.C., queda claro que, entre el último día de la vida de Isidoro, en el que voló a gozar de la eternidad feliz, y el inicio del obispado de Honorato, pasaron treinta y ocho días. Así, pues, ¿de qué modo, en tan poco espacio de tiempo, podían sucederse los funerales de Isidoro, la elección de Teodisclo, su acusación de hereje, su deposición del cargo sinodal y nuevamente la elección de Honorato? Queda pues probado que hay que mandar a navegar a Anticira a aquellos que se lo inventan. $\mathrm{Li}$ beremos a la santa iglesia hispalense, mancillada por la fama de un obispo tan ignominioso, echando al ficticio Teodisclo del álbum de sus pontífices ${ }^{36}$.

35 Sabemos que fue el sexto ( 638 d.C.), y no el quinto el concilio de Toledo al que asistió Honorato.

${ }^{36}$ Habes itaque ab hoc antiquissimo epigrammate perspicuum fidei solidissimae nostrorum fragmentorum testimonium: quae si nec aliunde fulcirentur, omnem ab ipsis amovere $<n>t$ imposturae suspicionem: quantique faciendum sit, aequi antiquitatis aestimatores arbitrabuntur. Eius ope iniuriam sanctissimae Ecclesiae Hispalensi illatam, suffecto Theodisclo, sanctissimo Praesuli Isidoro, pro pulsabimus. Et quamvis Autores Hispani, exteriq; de anno mortis D. Isidori inter se discrepent, certissimo calculo assero de mortuum esse anno Christi Dcxxxvi. qui rite incidit in Eram DCLXXIIII. Ita Redemptus Isidori discipulus, qui praesens ad fuit, Codexq; ille Nicolai Fabri, ubi Leandri, Isidori, et Florentinae sanctissimorum fratrum epitaphia continentur, testatum habent: quamvis quo ad D. Leandri obitum, haud sincere scripta in eo sit Era DCXLI. cum decessisset Era DCXXXIII. Sed D. Isidori diem obitus accidisse pridie Nonas Apriles Era DCLXIIII. Ex eodem praeterea Redempto facili negotio probatur, certum Isidori obitus annum fuisse ipsum Dcxxxvi. Etenim ille Isidorum inducit, quatriduo ante mortem, populum sic aloquentem: Ita ut sacri fontis unda, quam hodie devotus est populus percepturus sit vobis in remisionem peccatorum: et hoc osculum inter me et vos maneat in testimonium futurorum. Completis his omnibus, ad cellullam reductus est: et post diem confessionis, vel poenitentiae, quartum, pastoralem iugiter curam, et finem suum consummavit in pace. Amen. Sub die pridie Nonas Aprilis Luna XIX. Era D C L XXIV. At si paschales syclos consu-
Caro se reafirmará en su postura de defensa de la autenticidad de los versos de Tajón en su obra Antigüedades y Principado de la ilustríssima ciudad de Sevilla ${ }^{37}$, escrita siete años después, donde insiste en el hecho de que la aparición de la piedra sepulcral del obispo Honorato demuestra la antigüedad del culto en la sede sevillana, con anterioridad a la invasión musulmana.

Ya antes, en 1630 (tres años después de que en los Fragmenta del Cronicón de Máximo se editara el epigrama de Tajón que excluía completamente a Teodisclo de la silla episcopal sevillana gracias a un carmen sepulcrale y a su materialización en un mármol que se hallaba por aquel entonces en la biblioteca del ilustre Juan de Torres, teólogo de Sevilla), se hace sin embargo de nuevo necesario legitimar la autenticidad de esta inscripción.

Como consecuencia de ello y para dar fe de la lápida se edita un opúsculo dedicado a Gaspar de Guzmán, conde de Olivares, escrito por Francisco Fernández Bertrán, abad de la iglesia colegial de este condado, tras haber celebrado una reunión con otros doctores; entre ellos no faltó Rodrigo Caro. La obra lleva un elocuente título que hace hincapié en la identidad del personaje y en el lugar del hallazgo (Comprobación de la piedra sepulcral del venerable Honorato sucessor del glorioso doctor S. Isidoro arçobispos de la S. Iglesia Cathredal, y Metropolitana de Sevilla, hallada en un fundamento de los Reales Alcaçares della) y va precedida por una cita de Paulo Orosio que es un elogio de la lux veritatis $^{38}$.

las, isto anno sane reperies, Pascha fuisse pridie Kal. Aprilis, et ita baptismum catecumenorum solemnem quatriduo praecessisse Isidori mortem. Est et alia ratio, qualis omnis perimitur: nam D. Idori obitum quarto die Aprilis fuisse, certi iuris est, et in hoc omnes conveniunt, et anno 2. Chintilae Regis, qui est Christi Dcxxxvii mense Ianuario, Honoratus Praesul Hispalensis subscribit Concilio 5. Toletano, ergo iam antecessor Isidorus descesserat? Cum ergo Honoratus vixerit in honore pontificatus annos quinque, et menses sex, mortuusque sit pridie idus Novembris, Era DCLXXIX, qui est annus Christi DCXLI, liquido constat inter D. Idori supremum diem, quo ad beatae peremnitatis usuram evolavit, et Honorati inaugurationem, intercurrisse dumtaxat triginta, et octo dies. Quo ergo pacto tam parva temporis intercapedine, Isidorus sepulturae mandari, eligi Theodisclus, convinci haereticus, deponique a Synodo potuit, denuoque Honoratus eligi? Restat igitur, ut qui hoc comminiscuntur, Anticyras navigare mandemus. Et Sanctam Hispalensem Ecclesiam tam foedi Praesulis opinione pollutam, ab ipsius Pontificum albo Theodisclum confictum eiicientes, liberemus.

${ }^{37}$ Antigüedades y Principado de la Ilustrissima Ciudad de Sevilla y Chorographia de su convento iuridico, o antigua chancilleria dirigida al excelentissimo señor Don Gaspar de Guzmán, Conde Duque de Sanlucar la Mayor, Sevilla 1634.

${ }_{38}$ Paulo Orosio, Adversus paganos, 6, 1: O quanta est lux veritatis, si non adversus eam, ultro sese offerentem imbecilli infoeliciter oculi clauderentur. 
Ya en las primeras líneas de su introducción resultan sorprendentes las divergencias entre las noticias del hallazgo proporcionadas por Caro en sus Additiones a la Crónica de Dextro y las que aquí se ofrecen. Arias Montano ha desaparecido en el historial de esta pieza. Fernández Bertrán cuenta que en muchísimas ocasiones había visto y leído una piedra que parecia sepulcro de prelado en los Alcáceres. Se trataba de una inscripción a quien faltava un pedaço, con el titulo y nombre, la cual -añade- estuvo en el patio segundo, como se entra por la Monteria, arrimada al quarto del Rey D. Pedro ${ }^{39}$. En la declaración en latín que sirve de comprobación, situada al final del opúsculo, se precisa que Fernández Bertrán había visto esta inscripción desde 1592 en adelante ${ }^{40}$. Mientras que Caro afirmaba que fue Arias Montano quien halló la pieza entre unos materiales de derribo de unos edificios que no concreta, Fernández Bertrán cuenta que, tras preguntar a unos oficiales del Alcázar de dónde había salido la piedra y si por casualidad había otro fragmento, supo que la inscripción había aparecido mucho tiempo atrás en un fundamento del Alcázar y que no habían visto otro fragmento. Como no se explicaba cómo podía haber aparecido en los fundamentos del Alcázar una lápida que correspondía a un obispo quizá de Hispalis, un anciano respondió diciendo que no era extraño, pues, cuando se empezó a edificar la catedral (...), muchas lápidas, instrumentos o cosas del lugar (...) fueron llevados de la antigua iglesia al Alcázar para su aprovechamiento o restauración ${ }^{41}$.

Según este autor, en el año 1604 Diego Núñez Pérez, alcaide y veinticuatro de la ciudad de Sevilla, hizo que se llevara a su casa la lápida, de donde corrió otras fortunas ${ }^{42}$ hasta que la llevó a la suya el doctor Juan de Torres y Alarcón, presbítero y teólogo hispalense, perito en antigüedades, quien identificó la piedra que parecía de prelado con la inscripción sepulcral íntegra del obispo Honorato escrita por Tajón, que había encontrado in Flavii Lucii Dextri, M. Maximi et aliorum ${ }^{43}$, es decir, precisamente los que editó Caro en 1627. Fernández Bertrán además insiste en constatar que, estando en

${ }^{39}$ Op. cit., f. 2.

${ }^{40}$ Op. cit., f. 12: ab anno millesimo quingentesimo nonagesimo secundo, quo Hispalim primo ingressus sum, et aliquibus sequentibus.

${ }_{41}$ Op. cit., f. 13: Cui respondit senior quidam in haec verba: De hoc non miramur, quando enim Ecclesia illa (respiciens Cathedralem, quae fere nihil ab arce distat) aedificare coepit, plures lapides, res, et instrumenta (ut a maioribus accepimus) ab Ecclesiae antiquae loco in hanc arcem traducta sunt, eorum elaborationis, vel aservationis gratia.

${ }^{42}$ Op. cit., f. 2.

43 Op. cit., f. 13
Madrid, había tenido la ocasión de leer el carmen de Tajón, el cual relacionó, sin dudarlo, con aquella piedra que tantas veces había visto en el Alcázar. De todas las diferencias que hemos comentado más arriba entre ambos textos, la única que llama la atención a Bertrán es la ausencia en la piedra del tercer hexámetro, afirmando que quizá el ejecutor del testamento del obispo o bien el encargado de las pompas fúnebres lo omitiera por ser su contenido poco adecuado a una laudatio funebris (vita fuit melior lingua, sed lingua modesta).

Concluye la comprobación de la piedra haciendo una identificación histórica de los personajes en cuestión: por un lado, Honorato, que suscribe el concilio sexto de Toledo, santísimo sucesor de san Isidoro, quien presidió y suscribió el cuarto; por otro, Tajón, quien estuvo en el octavo y fue enviado por el séptimo a Roma para buscar el libro de los Moralia del santo papa Gregorio, perdido en Hispania, que encontró en la iglesia de San Pedro tras haber tenido una visión milagrosa. Se regocija además Fernández Bertrán de que los hispanos, que, de manera parecida, habían perdido parte de la obra de Dextro y sus socii, la hayan encontrado y comprobado con la intervención, según parece, del propio Tajón ${ }^{44}$.

Antes de firmar la declaración, insiste en que ya en 1624 , cuando hacía prácticamente veinte años que no veía la inscripción, anotó una versión resumida de estas conclusiones en el margen de un ejemplar de la Crónica de Dextro y Máximo que se conservaba en Madrid en la Biblioteca del Conde Duque. Esta última observación podría resultar algo sorprendente si no fuera porque sabemos que circulaba el rumor de que la piedra de Honorato había aparecido con posterioridad al carmen Taionis, rumor que ni siquiera podrá acallar la publicación del opúsculo de Fernández Bertrán ${ }^{45}$.

De todos modos, en la discusión acerca de la autenticidad de uno u otro texto se acabará imponiendo una nueva opinión defendida por Nicolás Antonio ${ }^{46}$, que invertía el proceso: lo falso es el tex-

\footnotetext{
${ }^{44}$ Op. cit., f. 14.
}

45 Véase al respecto la carta de 1658 de Nicolás Antonio citada en nota 30

${ }_{46}$ Bibliotheca Hispana Vetus, t. I, p. 424, c. 721: Huius carmen in sepulcro apponendum Honorati, quem germanum suum Caesaraugustanumque vocat atque insuper Hispalensem archiepiscopum, in additionibus ad Maximi Chronicon legimus. Epitaphium certe quoddam in lapide Hispalensi semeso atque divulso servatum fuit mutilum a Benedicto Aria Montano, posteaque a Joanne de Torres, uti refert in Notis ad hocce carmen Rodericus Carus; sed neque in illo Honorati nomen, nec Hispalis urbis mentio ulla. Insuper, non omnino conveniunt epitaphium hocce lapidi insculptum in iis quae legi possunt, et epitaphium quod Taioni tribuitur, quod 
to transmitido literariamente, fabricado por alguien que, tras haber visto el carmen grabado en la piedra, habría suplido las lagunas existentes y lo habría reelaborado de tal modo que pareciera un epitafio del obispo sevillano escrito por Tajón ${ }^{47}$.

A partir de Nicolás Antonio, no se vuelve a poner en duda la autenticidad de la inscripción y, o bien no se menciona en absoluto el supuesto carmen de Tajón o bien, retomando la vía abierta por este estudioso y sirviéndose también de algunos elementos de crítica textual a partir de las divergencias entre ambos textos, se denuncia la impostura de quienes en nombre de Tajón dieron completo y divergente el epigrama de Honorato. En esta última línea se sitúa la opinión de Flórez ${ }^{48}$, nunca puesta en entredicho por los investigadores que se han ocupado tanto de la inscripción como del personaje hasta la actualidad. Solamente dos nuevas alusiones al mármol de Honorato nos permiten sospechar que los testimonios sobre este personaje seguían abriendo interrogantes. Cronológicamente la primera se debe al padre J. Cevallos ${ }^{49}$ y está en una carta a G. Mayans fechada en 21 de marzo de 1752, donde le pide opinión sobre si la inscripción que se dice ser de Honorato, lo es, al tiempo que le envía una copia sacada con la mayor exactitud, a lo cual G. Mayans ${ }^{50}$ responde a 13 de mayo de 1752 que la inscripción de que Vm me habla me parece mиy

utique necessarium esset unum ut existimaretur idemque Taionis carmen Honorati sepulcro destinatum. Quare potius credimus fabricatum hoc Taionis nomine carmen sepulcrale ab eo qui vidisset Hispali aut exemplum habuisset mutilae illius inscriptionis ab Aria Montano inventae, atque deletas et fugientes litteras ex coniectura eum supplevisse, ut inscriptio esset Honorati episcopi Hispalensis sepulcro adaptata. Cuius cogitationis nostrae censuram eruditis viris relinquimus examinandam. Certe Rodericus Carus in nota ad hocce epitaphium suppositionem et imposturam clarissime arguit. Sin duda alude Nicolás Antonio a las palabras de Caro del folio $233 \mathrm{v}$. de las Additiones a los Fragmenta publicados en 1627: Habes itaque ab hoc antiquissimo epigrammate perspicuum fidei solidissimae nostrorum fragmentorum testimonium: quae si nec aliunde fulcirentur, omnem ab ipsis amoveret imposturae suspicionem: quantique faciendum sit, aequi antiquitatis aestimatores arbitrabuntur (aunque no queda claro si se trata de una mala interpretación del texto por parte de Nicolás Antonio, hecho, por lo demás, muy sorprendente tratándose de él, o de una denuncia explícita de la propia credulidad de Rodrigo Caro ante una impostura que se denuncia por sí misma).

47 Es cierto que algunos de los motivos temáticos del epigrama de Honorato atribuido a Tajón parecen inspirarse en el carmen escrito por Tajón como introducción a sus Sententiae. Véanse al respecto en nota 32 términos como regnum conferre beatis, y sobre todo sublimis anima, conscende ad regia coeli, que podrían ponerse en relación, respectivamente, con ossa beata tenet $\mathrm{y}$, sobre todo, con spiritus astra tenet.

${ }^{48}$ Flórez 1860: 236, n 25

49 Mestre 1990: 185, $\mathrm{n}^{\circ} 79$

${ }^{50}$ Mestre 1990: 190, $\mathrm{n}^{\circ} 82$ probable que es de Honorato metropolitano de Sevilla. La segunda alusión es una simple pregunta que se hace Schlunk en sus schedae manuscritas ${ }^{51}$, en las que anota al pie de una foto (véase fig. 4): In Buchstabenformen sehr fortgeschritten. Sicher Original?

Sicher Original? era la pregunta que se formulaba Schlunk, quien seguramente no se dio cuenta de una curiosa coincidencia: un códice del siglo XIV nos ha transmitido un texto de Vercelli que estuvo grabado en la tumba de un obispo llamado Honorato, sucesor de S. Eusebio $(\dagger 371)$. En aquel entonces la inscripción se hallaba colocada en un sarcófago situado en el altar de la Virgen. En 1581 se descubrieron en la basílica de S. Eusebio cuatro sarcófagos de mármol y uno de ellos se dijo, por parte de algunos, que era el de Honorato ${ }^{52}$. El texto transmitido por el códice era un epígrafe ${ }^{53}$ doble que decía lo siguiente:

Pontificis sancti cineres tenet Honorati arca hominis vilis quae manet ingenio

Hunc sanctum docuit nutrivit pastor alumnus

Egregius martyr presul et Eusebius

5 Exilii penas et carceris iste subivit

Discipulus carus et socius pariter

Ambo fide digni meritis et nomine patres

Cum Christo iuncti premia summa tenent.

Tertius hanc urbis sedem tenuit Honoratus

10 Antistes cuius spiritus astra tenet

Eusebius presul primus qui martyr alumnus

Celorum postquam regna beata petit

Hic pater ecclesiam docuit hanc dogmate recto

Sermones complens actibus ipse suos

Terris ac celo coniunctus ubique magistro

Eusebio consors hic Honoratus adest.

Las similitudes con el carmen sevillano de Honorato son tan evidentes que es imposible no ponerlos en relación. No podemos calcular el impacto que pudo tener el descubrimiento de las tumbas de Vercelli y cómo podrían haberse difundido los textos, pero tanto el carmen Taionis como el carmen sevillano parecen dejar clara la fuente de inspiración.

En efecto, si comparamos los tres textos, los paralelismos afectan tanto a la forma como al conte-

51 Conservadas en el Centro CIL II. Universidad de Alcalá.

${ }_{52}$ Picard 1988: 312-313.

53 ILCV 1050 A y B; CIL V 6722; CLE 1425 A y B. Damos el orden según Picard 1988: 312-313, nota 2, para quien el orden de los textos correctos es éste y no el que publicó Diehl. Según Picard, las dos partes estaban dispuestas una al lado de otra sobre la tapa de la sepultura o en la fachada del sarcófago, o bien una en la tapa y otra en la fachada. Montfaucon, a finales del siglo XVII, ya sólo vio la segunda parte de la inscripción. 
nido y, si fijamos nuestra atención especialmente en los dos textos de transmisión manuscrita, veremos además un tratamiento muy similar de los personajes y de la relación que entre ellos se establece. Vayamos por partes.

En el plano formal, cabe señalar no sólo que todos los carmina están escritos en dísticos elegíacos, sino que las concomitancias léxicas son demasiado abundantes para ser fruto simplemente de la casualidad. Baste señalar expresiones y cláusulas del tipo Pontificis sancti cineres tenet Honorati arca (1. $1 \mathrm{y}$ 2), premia summa tenent (1. 8), hanc urbis sedem tenuit Honoratus (1. 9), spiritus astra tenet (1. 10) o regna beata petit (1. 12) de los textos de Vercelli para establecer una dependencia casi necesaria con el léxico que aparece en los carmina de Sevilla: ossa beata tenet, spiritus astra tenet, corpus in urna iacet, en el caso del carmen Taionis, y communi sede beata tenes, spiritus astra petit, corpus in urna iacet, en el caso del carmen conservado en piedra. Más allá de un uso de tópicos literarios bien conocidos y que ya hemos analizado, los loci similes léxicos están fuera de cualquier duda.

Desde el punto de vista conceptual, no podemos pasar por alto que los carmina de Vercelli son claramente conmemorativos y, por lo tanto, no pueden considerarse epitafios, pero ya señalábamos que el carácter híbrido de nuestros textos hispalenses constituye una singularidad que los deja a medio camino entre el elogio y el epitafio. Desde este punto de vista, compartirían aspectos temáticos, pero quizá no funcionales. El más evidente, sin duda alguna, es el tratamiento de la dicotomía cielo / tierra y cuerpo /espíritu, además de lâ reelaboración cristiana de los felices reinos virgilianos, elementos todos ellos bien reflejados en el léxico común a los tres textos.

El «espíritu» de los dos carmina conservados en códice es también el mismo. Ambos obispos no sólo comparten el nombre, sino también la gloria de ser sucesores de prelados ilustres, cuya vida y obra forman merecida parte de la historia eclesiástica y literaria. En efecto, Honorato de Vercelli es presentado como sucesor de San Eusebio ${ }^{54}$, insistiendo el carmen en la relación que se establece entre ellos (hunc sanctum docuit nutrivit pastor alumnus egregius martyr presul et Eusebius / discipulus carus et socius pariter / ambo fide digni meritis et nomine patres / terris ac celo coniunctus ubique magistro Eusebio consors hic Honoratus adest). Lo mismo

${ }^{54}$ Bulhart, V. (ed.) 1957: Eusebii Vercellensis episcopi quae supersunt, Tunhout ( $C C$, series latina, IX). Se conserva también un carmen acrostichum del obispo Eusebio editado, entre otros, por Bücheler (CE 704). ocurre con Honorato de Sevilla, que tiene el honor de suceder también a un personaje «ilustrado» (praesul Honoratus successerat hic Isidoro). No insistiremos más en todas estas «casualidades».

Si el culto de Honorato en Vercelli data, según Picard ${ }^{55}$, de finales del siglo x o principios del XI y el propio texto no se transmite antes del XIV, cuesta creer que carmina epigraphica similares se encuentren en Hispania ya en el siglo viI.

\section{REINTERPRETACIÓN DEL TITULUS}

Recapitulando, quisiéramos enumerar una serie de puntos que convierten la inscripción de Sevilla atribuida a Honorato en un documento plagado de dudas cuya fiabilidad no puede mantenerse en el estado actual de conocimientos.

Las singularidades del soporte que ya se han comentado impiden, de momento, explicar satisfactoriamente su funcionalidad y su cronología, pues combinan elementos técnicos y decorativos anacrónicos entre sí y respecto a la cronología de Honorato. La paleografía tampoco es exclusiva de la época en que vivió el obispo y muchas de sus características se hallan sobre todo en inscripciones y códices mozárabes. La ordinatio es más habitual en los códices que en los tituli.

También las singularidades del texto lo convierten en un poema de difícil clasificación y con problemas sin resolver que afectan tanto a la forma como al contenido y que no permiten extraer con seguridad ninguna conclusión cronológica.

Por último, tanto los datos del hallazgo del mármol de Honorato como la trayectoria histórica de las fuentes documentales a las que se recurrió para relacionarlo con dicho obispo son elementos decisivos para reafirmarnos en que todas las dudas planteadas por el soporte, la paleografía, la ordinatio y el texto no eran ni son infundadas. Nada parece casual y

55 Picard 1988: 672-673: À la fin du X siècle ou au début du XI s., Verceil rend un culte à deux autres de ses évêques, dont les anniversaires furent ajoutés sur l'exemplaire du Martyrologe de Raban Maur copié à cette époque dans la cité épiscopale [Bibl. capitolare de San Eusebio de Verceil, $\mathrm{n}^{\circ}$ LXII; éd. J. McCulloh, CC, cont. med., 44 p. 109 (28 oct.) et 91 ( 11 sept.) daté de la fin du X siècle par Ferrari, et du second quart du XI siècle par l'éditeur (p. XLVI, n. 25)]. Tous deux étaient inhumés à San Eusebio. Le premier d'entre eux est Honoratus, troisième évêque de Verceil. Nous connaissons le texte d'une inscription commémorative, où il est présenté comme le disciple du martyr Eusebius, son compagnon de prison et d'exil. Il est impossible de dire à quelle époque on a commencé à célébrer le culte d'Honorius (sic), car cette inscription, qui est d'ailleurs difficile à dater, ne lui donne que l'épithète de "saint», et non celle de "confesseur», et encore moins de martyr. 
todo cobra sentido si reinterpretamos el mármol de Honorato en el contexto de su «descubrimiento».

La aparición en los Fragmenta añadidos al Cronicón de Máximo, apócrifo compuesto por Román de la Higuera ${ }^{56}$ en la transición del siglo XVI al XVII, de un carmen atribuido a Tajón, que sirve para legitimar tanto el Cronicón como el sepulcro del obispo Honorato sucesor de Isidoro; el carácter espurio del carmen supuestamente escrito por el obispo de Zaragoza Tajón, ficción indudable; las contradicciones y peripecias que rodean el hallazgo y que no son exclusivas de esta pieza - pues una historia similar refiere Villanueva ${ }^{57}$ en relación con el descubrimiento a fines del siglo xVI de la inscripción de Santa María de la Catedral de Toledo ${ }^{58}$ _... Todo ello se explicaría en el ambiente cultural, religioso y político de principios del XVII, en plena Contrarreforma. Sólo con la lectura de los textos de Caro o Bertrán se percibe perfectamente la atmósfera que se respiraba al inicio de dicho siglo en la capital andaluza, al igual que en otros lugares de España. El fervor popular estaba ansioso de descubrimientos de reliquias, de milagros y de todo tipo de profecías. Cualquier cosa que sirviera para exaltar la fe era bienvenida. En este marco reaccionario, se producen algunas de las falsificaciones más célebres de la historia de España, como los plomos del Sacromonte ${ }^{59}$ o los cronicones, plagados de invenciones de reliquias o reivindicaciones de santos acompañadas siempre, con tal de legitimar los hechos, de grandes prodigios reveladores. A esto se añade la necesidad de probar la antigüedad de los emplazamientos de las catedrales o iglesias principales, y, en consecuencia, de sus mártires, santos y obispos. Se trataba, en definitiva, de insistir en que, antes de la presencia musulmana, aquellos lugares ya eran sagrados y que habían desempeñado una función muy destacada en la historia eclesiástica del reino visigodo. En este sentido, es especialmente relevante el resurgimiento de antiguas polémicas sobre las primacías episcopales. Una de ellas, que arranca de la crónica de Lucas de Tuy, del siglo XII, pretendía, como hemos indicado, que Toledo había

56 Ya Godoy Alcántara, en su Historia de los falsos cronicones, del año 1868 , ofreció una síntesis razonada de toda la obra apócrifa del Padre Jerónimo Román de la Higuera, el famoso jesuita del siglo xvI, autor de tantas ficciones. Véase Godoy 1981: 17-43, Caro Baroja 1992: 163-187. Señalemos también la denuncia de los falsos cronicones llevada a cabo por Nicolás Antonio en su obra Censura de historias fabulosas, publicada póstumamente en Valencia en 1742.

57 Villanueva 1804: $159 \mathrm{ss}$.

58 IHC 155; ICERV 302; Duval 1993: 184, 185, 192 y 193 sospecha que pueda tratarse de un falso del siglo XVI.

${ }^{59}$ Para los falsos del Sacromonte de Granada, $c f$. Caro Baroja 1992: 115-158 y Godoy 1981: 44-128. arrebatado a Sevilla este privilegio, como consecuencia de la actuación infame de uno de los obispos hispalenses, Teodisclo, un griego hereje, experto en lenguas, que el Tudense consideraba sucesor de Isidoro. De ahí la maldición que R. Caro dirige no sólo a este hereje sino a todos aquellos que pretenden mantenerlo en su silla, mancillando así a la santa Iglesia de Hispalis. El epígrafe atribuido a Honorato venía a arreglar una situación desespera$\mathrm{da}$, en la medida en que, por sus menciones cronológicas, desterraba para siempre la posibilidad de que Teodisclo hubiera ocupado la sede sevillana tras la muerte de Isidoro. Si nos detenemos un momento en el análisis del contenido, no sólo de la inscripción conservada en piedra sino del carmen Taionis, en sus líneas podría subyacer alguna alusión a esta polémica (vita fuit melior lingua, sed lingua modesta; non timet ostiles iam lapis ste minas; nunc ovat hostiles nec timet ille minas).

Paralelamente a este fenómeno religioso, Sevilla se había convertido, gracias a la personalidad del Conde Duque, en la receptora por excelencia de todo lo clásico. La recuperación de manuscritos, las ediciones de textos antiguos, el interés por nuevos descubrimientos arqueológicos y por el coleccionismo dan buena prueba de ello. No es imposible que, en un ambiente donde la circulación de antigüedades en los círculos eruditos era algo cotidiano, pudiera concebirse un fraude materializándolo en un soporte de aspecto antiguo, hipótesis que creemos no poder descartar después del análisis que hemos llevado a cabo ${ }^{60}$.

El verdadero problema radica en poder situar en qué momento es concebida la pieza, en la medida en que las incoherencias cronológicas de los distintos elementos descartan una datación sincrónica a la vida de Honorato, en torno al 638, año de celebración del VI Concilio de Toledo que él suscribe. Si nos atenemos estrictamente a las características materiales, propondríamos que en época mozárabe se pudo reaprovechar un elemento arquitectónico antiguo para honrar la memoria de un obispo. Esto lo aconsejan sobre todo la talla plana y la paleografía. Pero en contra de esta datación estarían la forma y función del soporte, así como los motivos decorativos de la parte inferior, que nos llevan a una cronología moderna con la que sí se avienen plenamente las razones historiográficas y sobre todo el año del descubrimiento de los sepulcros de Vercelli.

${ }^{60}$ Por otra parte, el fenómeno de la falsificación epigráfica es una práctica muy difundida en la cronología en la que nos movemos. $C f$. al respecto las observaciones de Grafton 1993: $35-40$ 


\section{BIBLIOGRAFÍA}

Antonio, N. 1788: Bibliotheca Hispana Vetus, Madrid (trad. cast. Madrid 1998, 4 vol.).

BovinI, G. 1954: Sarcofagi paleocristiani di Ravenna, Ciudad del Vaticano-Roma.

BÜCHELER, F. 1895-1897: Carmina Latina epigraphica I-II (=CLE), Leipzig.

Bulhart, V. (ed.) 1957: Eusebii Vercellensis episcopi quae supersunt, Tunhout $(C C$, series latina, IX).

CARo, R. (ed.) 1627: Flavii Lucii Dextri V.C. Omnimodae Historiae quae exta(n)t fragmenta cum Chronico M. Maximi et Helecae ac S. Braulionis Caesaraugustanorum episcoporum notis Roderici Cari Baetici illustrata anno. MDCXXVII Hispali apud Mathiam Clavigium, Sevilla.

CARO, R. 1634: Antigüedades y Principado de la Ilustrissima Ciudad de Sevilla y Chorographia de su convento iuridico, o antigua chancilleria dirigida al excelentissimo señor Don Gaspar de Guzmán, Conde Duque de Sanlucar la Mayor, Sevilla.

CARo Baroja, J. 1992: Las falsificaciones de la Historia (en relación con la de España), Barcelona.

Colafrancesco, P. y Massaro, M. 1986: Concordanze dei Carmina Latina Epigraphica, Bari.

Delgado, F.X. 1822: Dibujo en manuscrito Biblioteca Colombina 84-4-47 (Sevilla).

DiEHL, E. 1925-1931: Inscriptiones Latinae christianae veteres $(=I L C V)$ (3 vol.), Berlín.

Duval, Y. 1993: Projet d'enquête sur l'épigraphie martyriale en Espagne romaine, visigothique (et Byzantine), Antiquité Tardive I, 173-206.

Fernández Bertrán, F. 1630: Comprobación de la piedra sepulcral del venerable Honorato suces sor del glorioso doctor S. Isidoro arçobispos de la S. Iglesia Cathedral, y Metropolitana de Sevilla hallada en un fundamento de los Reales Alcaçares della al excmo señor Don Gaspar de Guzman alcaide perpetuo dellos, Conde de Oliuares, Duque y Marques et c. Gran Consejero del Serenisimo D. Felipe Quarto nuestro Señor, Rei Catolico de las Españas y de las Indias, Sevilla.
FLóREZ, E. 1752: España sagrada IX, Madrid (3a edición, Madrid 1860).

Fontaine, J. 1959: Isidore de Séville et la culture classique dans l'Espagne wisigothique (2 vol.), Paris.

García Moreno, L.A. 1974: Prosopografía del reino visigodo de Toledo, Salamanca.

Godoy Alcántara, J. 1868: Historia crítica de los falsos cronicones, Madrid (Reimpresión Madrid 1981).

GonZÁleZ, J. 1991: Corpus de inscripciones latinas de Andalucía. Vol. II / Tomo II: Sevilla (= CILA), Sevilla.

Grafton, A. 1993: Faussaires et critiques. Créativité et duplicité chez les érudits occidentaux (trad. al francés de M. Carlier), Paris.

HÜBNER, E. 1871: Inscriptiones Hispaniae christianae $(=I H C)$, Berlin.

LAWRENCE, M. 1970: The sarcophagi of Ravenna, Roma.

Mestre SAnchís, A. 1990: Correspondencia de los ilustrados andaluces, Sevilla.

PICARD, J.-Ch. 1988: Le souvenir des évêques. Sépultures, listes épiscopales et culte des évêques en Italie du Nord des origines au X siècle, Roma (BEFAR 268).

REAL, L.M. 1995: Inovação e resistência: dados recentes sobre a antiguidade cristã no Ocidente Peninsular, IV Reunió d'Arqueologia Cristiana hispànica. IV Reunião de Arqueologia cristã hispânica (Lisboa 1992), Barcelona, 1768.

Schlunk, H. y Hauschild, Th. 1978: Die Denkmäler der frühchristlichen und westgotischen Zeit, Hispania Antiqua, Mainz am Rhein

Ulbert, T. y CABALLERO, L. 1976: La basílica paleocristiana de Casa Herrera, en las cercanías de Mérida (Badajoz) (Excavaciones Arqueológicas en España 89), Madrid.

Villanueva, J. L. 1804: Viage literario a las Iglesias de España, tomo III, Madrid.

VIVES, J. 1969: Inscripciones cristianas de la Espa$\tilde{n}$ a romana y visigoda $(=I C E R V)$, Barcelona. 